\title{
The individualization of treatment based on molecular markers
}

\author{
Vladimir M. Moiseyenko
}

Received: 5 October 2012 / Accepted: 10 October 2012 / Published online: 15 November 2012 (c) Springer-Verlag Wien 2012

\begin{abstract}
Recent developments have revealed various decisive discoveries in individualized oncology for many different entities-the individualization of treatment based on molecular markers representing just one of those milestones. The implication of epidermal growth factor receptor (EGFR) mutations for EGFR-tyrosine kinase inhibitor (TKI) treatment, the definition of the HER2 status in breast cancer and the application of the KRAS mutation analysis in colorectal cancer are examples for this development. All these activities have also been the major focus at the Cancer Research Institute in St. Petersburg, where I worked for many years. Within the last years, a growing connection between basic research activities and clinical application can be observed.
\end{abstract}

First of all, I want to state that it is great honor for me to have been endowed with the function of the Section Editor for Gastrointestinal Cancer in the Magazine of European Medical Oncology (MEMO). During the past few years, well-functioning networks of translational cancer research were developed within Central Europe. Various academic study groups such as the Central European Cognitive Science Association (CECOG) proved that by international collaboration, important steps toward new treatment paradigms can be achieved. Just to mention that CECOG activities set an example on maintenance therapy in lung cancer (Lung Cancer 2006), which has now rendered to be a state of the art procedure. It is my personal and challenging aim to transfer knowledge gained through basic research into clinical practice.

Prof. V. M. Moiseyenko, MD ( $\square)$

Diagnostic and Treatment Center under International Institute

for Biological Systems named after S.M. Berezin, 43, Karla Marksa Street, Pesochny, St. Petersburg, Russian Federation 197758

e-mail: moiseyenkov@gmail.com
Recent developments have revealed various decisive discoveries in individualized oncology for many different entities - the individualization of treatment based on molecular markers representing just one of those milestones. The implication of epidermal growth factor receptor (EGFR) mutations for EGFR-tyrosine kinase inhibitor (TKI) treatment, the definition of the human epidermal growth factor receptor 2 (HER2) status in breast cancer, and the application of the KRAS mutation analysis in colorectal cancer are examples for this development. All these activities have also been the major focus at the Cancer Research Institute in St. Petersburg, where I worked for many years. Within the last years, a growing connection between basic research activities and clinical application can be observed.

It will be my challenge to introduce translational activities of cancer research with special focus on gastrointestinal (GI) cancer to the readership of MEMO.

Yours

Vladimir M. Moiseyenko

Section Editor for Gastrointestinal Cancer

V. Moiseyenko is one of the leading medical oncologists of Russia, who worked in the Cancer Research Institute in St. Petersburg for many years. Now, since 2011, he is the head of the Oncology Department at Diagnostic Treatment Centre of the International Institute of Biological Systems named after Sergey Berezin (DTC IIBS) - a private oncology clinic. His research includes the development of methods of biotherapy, genetically modified and dendritic cells cancer vaccines [1], as well as individualized treatment of solid tumorsbased on molecular markers [2]. During the past years, he concentrated his research work on EGFR [3-6] and BRCA [7] mutations in various types of cancer, as well as c-KIT mutations in patients with mucosal melanoma [8]. Prof. Moiseyenko has participated actively in numerous trials and has published more than 250 scientific papers. 


\section{Conflict of interest}

The author declares that there is no actual or potential conflict of interest in relation to this article.

\section{References}

1. Moiseyenko VM, Danilov AO, Baldueva IA, Danilova AB, Tyukavina NV, Larin SS, et al. Phase I/II trial of gene therapy with autologous tumor cells modified with tag7/PGRP$S$ gene in patients with disseminated solid tumors. Ann Oncol. 2005;16(1):162-8.

2. Imyanitov EN, Moiseyenko VM. Invited critical review. Molecular-based choice of cancer therapy: realities and expectations. Clinica Chimica Acta. 2007;379:1-13.

3. Moiseyenko VM, Procenko SA, Levchenko EV, Barchuk AS, Moiseyenko FV, Iyevleva AG, et al. High efficacy of first-line gefitinib in non-Asian patients with EGFR-mutated lung adenocarcinoma. Onkologie. 2010;33(5):231-8.

4. Levchenko EV, Moiseyenko VM, Matsko DE, Iyevleva AG, Ivantsov AO, Yargnian SM, et al. Down-staging of EGFR mutation-positive advanced lung carcinoma with gefitinib followed by surgical intervention: follow-up of two cases. Onkologie. 2009 Nov;32(11):674-7.
5. Suspitsin EN, Levchenko EV, Moiseyenko FV, Ivantsov AO, Radzhabova SA, Matsko DE, et al. Rapid symptomatic improvement in gefitinib-treated patients with EGFRmutated lung cancer: possible role of downregulation of inflammatory molecules? Onkologie. 2011;34(10):559-60.

6. Iyevleva AG, Novik AV, Moiseyenko VM, Imyanitov EN. EGFR mutation in kidney carcinoma confers sensitivity to gefitinib treatment: a case report. Urol Oncol. 2009 Sep-Oct;27(5):548-50.

7. Imyanitov EN, Moiseyenko VM. Drug therapy for hereditary cancers. Hered Cancer Clin Pract. 2011 Aug 6;9(1):2-16.

8. Abysheva SN, Iyevleva AG, Efimova NV, Mokhina YB, Sabirova FA, Ivantsov AO, et al. KIT mutations in Russian patients with mucosal melanoma. Melanoma Res. 2011 Dec;21(6):555-9. 